\title{
Expression of the Tyrosinase Gene in Different Dromedary Camels of Saudi Arabia
}

\author{
Abdullah Sheikh ${ }^{1, *}$, Faisal Almathen ${ }^{1,2}$ and Hairul Islam Mohamed Ibrahim ${ }^{\mathbf{3}, \mathbf{4}}$ \\ ${ }^{1}$ The Camel Research Center, King Faisal University, P.O Box: 400, Al-Ahsa 31982, \\ Saudi Arabia \\ ${ }^{2}$ Department of Veterinary Public Health, College of Veterinary Medicine, P.O Box: 400, \\ Al-Ahsa 31982, Saudi Arabia \\ ${ }^{3}$ Department of Biological Sciences, College of Science, King Faisal University, P.O \\ Box: 400, Al-Ahsa 31982, Saudi Arabia \\ ${ }^{4}$ Pondicherry Centre for Biological Science and Educational Trust, Kottakuppam, India
}

\begin{abstract}
A B S T R A C T
Tyrosinase $(T Y R)$ gene has a role in regulating the pigmentation process and acts as a precursor for eumelanin or pheomelanin. There have been many studies that reported variations in this gene associate with the coat color of the animal. This is the first study of $T Y R$ gene expression analysis from various dromedary or Arabian camel (Camelus dromedarius) phenotypes from Saudi Arabia. The four camel groups included were white, diluted (light brown, creamy and fawn), black and dark brown representing eumelanin and pheomelanin coat colors. Generally, the TYR gene expresses less in non-pigmented than the pigmented species. The results of our study showed that the mRNA from skin biopsies has low expression in white dromedary camels while higher expression in dark brown phenotypes followed by black and diluted ones through real time quantitative PCR. MicroRNAs (miRNAs) miR-129-5p and miR145 were evaluated for their depigmentary role and observed reciprocal expression against the $T Y R$ gene expression. Hence the miR-129 and miR-145 expressed higher in non-pigmented camels compared to the pigmented ones and correlated with $T Y R$ expression. Our data provides useful information to understand the camel $T Y R$ role in coat color variation which is supportive in genotyping, genetic selection, breeding and classification.
\end{abstract}

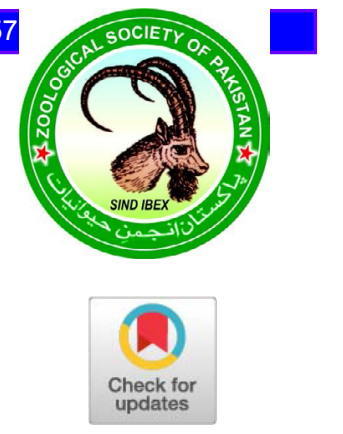

Article Information

Received 08 January 2021

Revised 13 Februay 2021

Accepted 21 Februay 2021

Available online 19 August 2021

Authors' Contribution

AS designed the work, AS and HI

carried out the experiments. FA

supervised the work and analyzed

the data. AS, FA and HI finalized the

manuscript.

Key words

Tyrosinase, Coat color, Dromedary camel, Micro RNA, miR-145.

\section{INTRODUCTION}

$\mathrm{D}$ romedary camel is an important livestock animal adapted to harsh desert environments (Eshra and Badawy, 2014). It is raised for milk, meat and wool production and its demand is increasing globally therefore integrating into the international economy (Faye and Bonnet, 2012; Faye, 2018). It is useful in agriculture, transport, racing, beauty contest and tourism. In Saudi Arabia, there are different phenotypic camels in various regions and they are mainly used in milk production, meat production and racing: black (majahim), white (wodh), brownish yellow (safrah), yellowish to red (hadahana), red to white (awadi), white (awarik), brown (hamrah), red (saheli), grey (shaele), grey (shageh), dark brown (sofor) and blue grey (zargeh) (Abdallah and Faye, 2012; Mahmoud et al., 2020).

It is important to characterize the coat color genes completely to understand their role due to the commercial value of specific phenotypes and breeding purposes.

\footnotetext{
* Corresponding author: asheikh@kfu.edu.sa 0030-9923/2021/0005-1939 \$ 9.00/0

Copyright 2021 Zoological Society of Pakistan
}

Tyrosinase is an enzyme that catalyzes the biosynthesis of melanin through various metabolic pathways producing quinone, which is the precursor for melanin pigmentation. It is encoded by the TYR gene and present in specialized cells such as skin, hair and eyes to provide pigmentation. It is present on the $10^{\text {th }}$ chromosome of the dromedary camel and spanning over 5 exons. It is generally known as albino locus due to variations in this gene cause Albinism in various species (Anello et al., 2019). There have been reported more than 100 mutations in the TYR gene with albinism due to the absence of melanin resulting in white color of hair and skin as well as the pale skin. It has been reported in other species including mice, cats, cattle, rabbits, buffalos, donkeys and others (Yokoyama et al., 1990; Beermann et al., 2004; Aigner et al., 2000; Imes et al., 2006; Damé et al., 2012; Schmutz et al., 2004; Utzeri et al., 2016). In this gene, there were some repeated sequences (Microsatellites) in the noncoding DNA, which may have a role in the gene transcription and phenotype pigmentation (Li et al., 2004; Sjakste et al., 2013).

The SNP c.428 A > G was higher in white coat color than other phenotypes (Anello et al., 2019). A point mutation in the TYR gene of chinchilla mice observed with greyish color (Lamoreux et al., 2001) and another point 
mutation resulted in platinum type phenotype (Orlow et al., 1993). Hypopigmentation was also observed in the body and eyes of mice (Challa et al., 2016). Some other mutations in this gene reported diluted phenotypes (Himalayan and chinchilla mice).

Some of the studies including Sudanese camel breeds, Egyptian, Pakistani and Saudi Arabian reported with the presence of different genotypes and snp's in the exon 1 of this gene (Mahmoud et al., 2020; Ishag et al., 2013; Nowier et al., 2020; Shah et al., 2009, 2012). One of the studies reported Arabian camels were classified based on their different phenotypic coat colors such as white, black, brown and dark brown (Almathen et al., 2018). A recent study on llamas has been reported with $T Y R$ gene polymorphism with regards to their coat color phenotypes (Anello et al., 2019). Different gene studies were carried out in camels to study the pigmentation variation in coat colors such as MC1R, ASIP (Daverio et al., 2016; Almathen et al., 2018), KIT (Holl et al., 2017). The variations in the coat color might be influenced by epigenetic factors such as methylation, miRNA and chromatin modifications. In this study, the involvement of miRNAs against TYR gene was evaluated.

MiRNAs are conserved, small and noncoding RNA's which regulate the gene expression by inhibiting the target mRNA at the post-transcriptional level. They bind to the target mRNA and inhibit the protein synthesis or overexpress the protein. Different miRNAs have been reported as regulating the melanogenesis such as miR434-5p and mir-25 were used to target TYR and MITF, respectively (Wu et al., 2008; Zhu et al., 2010). MiR145 has been reported with depigmentary activity by degrading the TYR mRNA expression in human and mouse melanocytes (Dynoodt et al., 2013). Therefore, its expression increased more folds in depigmented animals and decreased in pigmented animals. Similarly, miR-129$5 \mathrm{p}$ was expressed low in Inner Mongolia cashmere goats (white) and higher in Dazu black goats (pigmented) by regulating the TYR gene (Li et al., 2020). Naturally, miR$129-5 \mathrm{p}$ along with 53 other miRNAs that influence the pigmentation by regulating the TYR gene (Wu et al., 2008).

In this study, we analyzed $T Y R$ gene expression and its association with the coat colors of the different dromedary camels (white, black, diluted and dark brown) and investigated the miRNAs (129-5p and 145) to correlate with $T Y R$ mRNA expression.

\section{MATERIALS AND METHODS}

\section{Sample collection}

Animal ethics approval was obtained from the deanship of scientific research, King Faisal University. Dromedary camel samples $(n=16)$ white (wodh) (4), black (majahim) (3), dark brown (sufor) (4) and diluted (shual) (5) including male and female were selected based on their phenotypic variation from the Camel Research Center at King Faisal University is presented in Supplementary Figure S1. Animals prepared aseptic with iodine, shaved the selected area and marked. Lidocaine (2\%) was given as the local anesthesia subcutaneously then waited for $10 \mathrm{~min}$. Robbins Instruments Disposable Biopsy Punches $(3 \mathrm{Mm})$ were used to collect the skin samples by rotating gently without applying pressure and cutting the sample with surgical scissors. Iodine and antiseptic powder was applied to the wound and it was monitored further to check for any infections. The collected samples were placed in sterile tubes with icebox and transferred to the lab and stored at $-20^{\circ} \mathrm{C}$ until further processing.

Table I.- Primers used in PCR.

\begin{tabular}{|c|c|c|c|c|}
\hline $\begin{array}{l}\text { S. } \\
\text { No }\end{array}$ & Name & Primers $\left(5^{\prime} \rightarrow 3^{\prime}\right)$ & $\begin{array}{l}\text { Annealing } \\
\text { temp. }\left({ }^{\circ} \mathrm{C}\right)\end{array}$ & $\begin{array}{c}\text { Product length } \\
\text { (bp) }\end{array}$ \\
\hline \multirow[t]{2}{*}{1} & $T Y R$ & F: TCAGCTTTAGAAACACCCTGGA & 58.5 & 196 \\
\hline & & R: CTTCGAAGCCACTGTTCAAAAA & & \\
\hline \multirow[t]{2}{*}{2} & GAPDH & F: CCATGTTTGTGATGGGCGTG & 57.5 & 200 \\
\hline & & R: CATCTTCCCAGAGGGGCCAT & & \\
\hline \multirow[t]{2}{*}{3} & MiR-129 & F: CTCAACTGGTGTCGTGGAGTCCGGCAATTCAGTTGAGAGCAAGCC & - & - \\
\hline & & R: ACACTCCAGCTGGGCTTTTTGCGG & & \\
\hline \multirow[t]{2}{*}{4} & MiR-145 & F: CTCAACTGGTGTCGTGGAGTCCGGCAATTCAGTTGAGAGGGATTC & - & - \\
\hline & & R: ACACTCCAGCTGGGGTCCAGTTTT & & \\
\hline \multirow[t]{2}{*}{5} & U6 & F: GCTTCGGCAGCACATATACTAAAAT & - & - \\
\hline & (internal control) & R: CGCTTCACGAATTTGCGTGTCAT & & \\
\hline 6 & Universal primer & AACTGGTGTCGTGGAG & - & - \\
\hline
\end{tabular}

GADPH, glyceraldehyde-3- phosphate dehydrogenase; -, not applicable. 


\section{RNA isolation, cDNA and real-time PCR}

To study the $T Y R$ gene expression, skin biopsy samples from four coat color groups were obtained and followed the RNA Trizol ${ }^{\circledR}$ procedure was used to extract the total RNA from the skin biopsies and measured the RNA quality and quantity on nanodrop. cDNA was prepared with reverse transcriptase (Applied Biosystems, Vilnius Lithuania). Quantitative realtime PCR was accomplished by using a set of designed primers (Table I), the exon-exon region of the GAPDH housekeeping gene used as a control. The $12 \mu \mathrm{l}$ of the mix was prepared with PowerUp ${ }^{\mathrm{TM}}$ SYBR ${ }^{\mathrm{TM}}$ Green Master Mix (Applied Biosystems, Warrington, UK) $(6 \mu \mathrm{l}), \sim 500 \mathrm{nM}$ of primers, and cDNA as per the concentration and ran on PCR (Applied Biosystems ViiA 7 Real-Time PCR System). The program set for PCR was as follows; $50^{\circ} \mathrm{C}-2 \mathrm{~min}, 95^{\circ} \mathrm{C}-10 \mathrm{~min}, 40$ cycles of $95^{\circ} \mathrm{C}$ $-15 \mathrm{sec}, 60^{\circ} \mathrm{C}-1 \mathrm{~min}$ and final gradient 95 to $60^{\circ} \mathrm{C}$. The mRNA quantification of TRY and the endogenous control GAPDH with the fold change in the target mRNAs were calculated using the comparative $2^{-\Delta \Delta \mathrm{Ct}}$ method (Livak and Schmittgen, 2001). We selected miR-129-5p and miR-145 from the bioinformatic program TargetScan (http://www. targetscan.org) and synthesized from the Macrogen Inc., Korea (Table I).

\section{RESULTS}

TYR gene of the dromedary camel

We assessed the TYR gene of Saudi Arabian dromedary camels representing different coat colors. It has the predicted coding sequence of $1724 \mathrm{bp}$ and encodes a TYR protein with 574 amino acids. This protein is $99.67 \%$ identical with Camelus ferus (XM_006192400.2) and 99.55\% with Camelus bactrianus (XM_ 010973375.1$)$.

TYR expression in different dromedary camel phenotypes

The effect of TYR mRNA on camel coat color was measured using quantitative real time-PCR. The 300 ng of extracted RNA was used for cDNA preparation. This complete cDNA was quantified and used for the investigation of TYR expression. The results showed TYR gene expression was significantly higher in dark brown followed by black, diluted and lowest recorded in white dromedary camels representing higher expression in pigmented ones (Fig. 1). Diluted color strains have 8.5 fold higher expression against white camel species and it was significantly overexpressed $(\mathrm{p}<0.003)$. Moreover, the TYR mRNA expression was increased 7 fold in black camels compared to diluted strain camel $(p<0.001)$. A similar overexpression was observed in dark brown camels compared to black camel species. From the above findings, Dark brown has $>600$ fold higher TYR mRNA expression in when compared to white dromedary camel species (Fig. 1). Hence, it is clear that TYR mRNA was down regulated in non-pigmented individuals than the pigmented ones. It was further confirmed by posttranscriptional influencing factors.

\section{Identification and selection of miRNAs-miR-129-5p and miR-145}

The identification of TYR mRNA targeted miRNAs were by using a Targetscan tool. The preliminary findings showed a lack of miRNA evidence in dromedary camel species. So, the studies screened a ruminant based organism known as Bos taurus species. TYR mRNA sequences were used for the identification of miRNA and found 23 hits of miRNAs (http://www. targetscan.org/cgi-bin/targetscan/vert_72/view_gene. cgi? rs $=$ ENST00000263321.5\&taxid $=9913 \&$ showcnc $=$ $0 \&$ shownc $=0 \&$ shownc_nc $=\&$ showncf $1=\&$ showncf $2=$ \&subset=1). The evaluation of miRNA conservation score showed that, miR-129-5p and miR-145 has $>8$ mer conservation and high context ++ score compared to other miRNAs. Whereas, these two miRNAs were further analyzed for miRNA expression in various dromedary camel species. These findings are the first report on camel species.

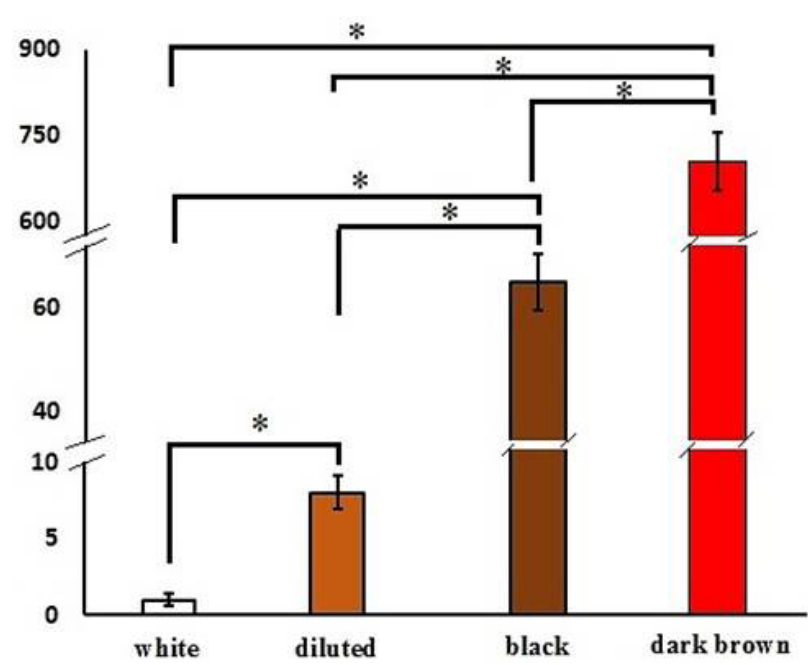

Fig. 1. TYR gene expression in skin biopsies of different phenotypic dromedary camels. Bar graphs showing increasing expression from white to dark brown phenotypes. * defines the statistically significant $(p<0.05)$.

MiR-129-5p and MiR-145 expression and their targeted $m R N A$

The identified miRNAs were evaluated of expression analysis. The two miRNAs (MiR-129-5p and MiR-145) were similar in expression against the mRNA of $T Y R$. 
They showed high expression in non-pigmented (where TYR is less) and low expression in pigmented camels (where TYR is high) as shown in Figure 2. The decreased expression order follows as diluted $>$ white $>$ black $>$ dark brown for miR-129-5p (Fig. 2A, B) and white $>$ diluted $>$
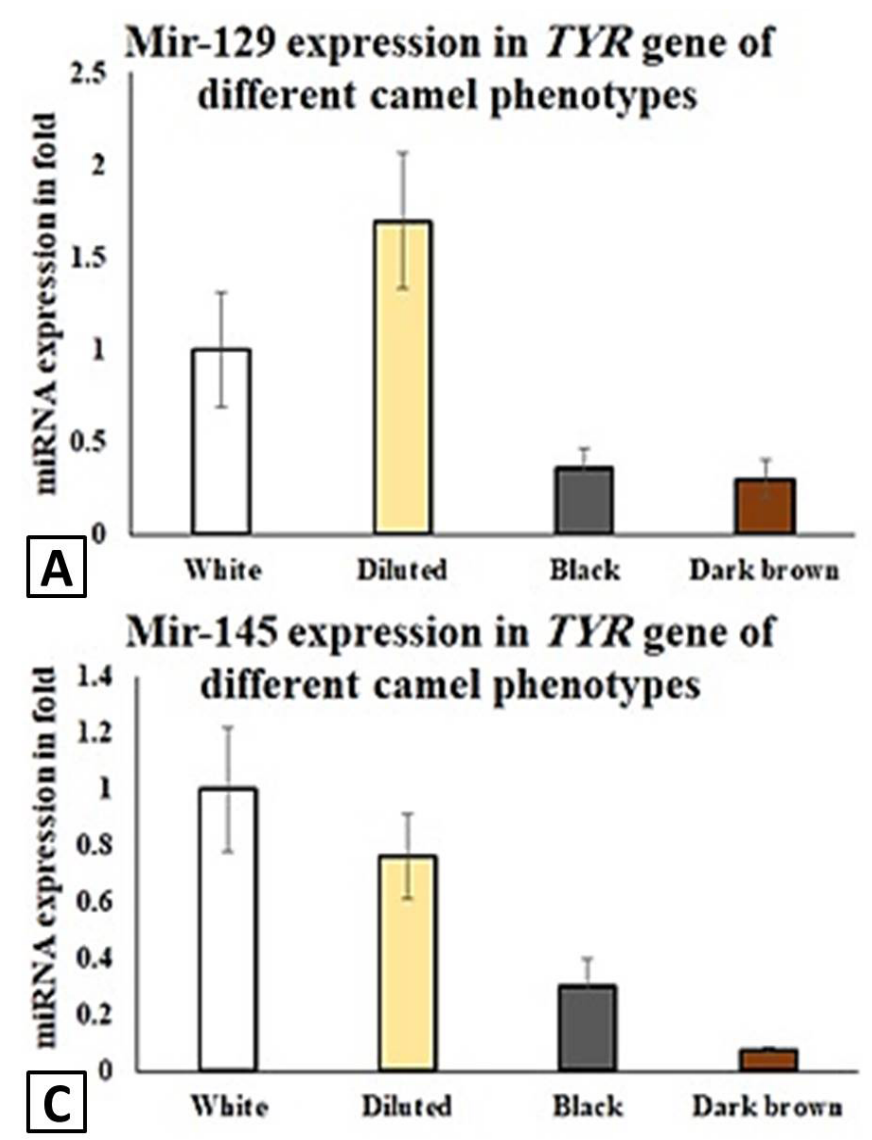

black $>$ dark brown for miR-145 (Fig. 2C, D). These two miRNAs bind to the mRNA of the TYR gene at 3' UTR regions and downregulate the $T Y R$ expression (Fig. 1). The binding of miRNAs to the TYR mRNA is shown in Figure 3.
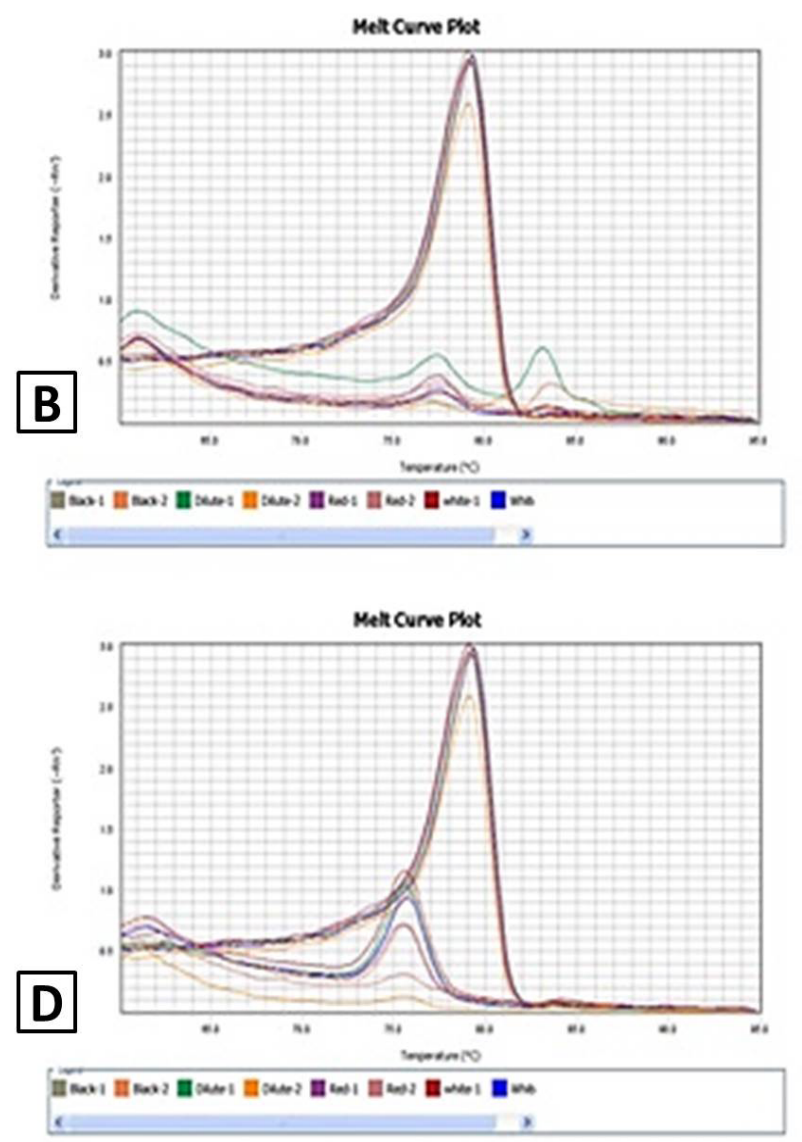

Fig. 2. A, MiR-129-5p expression in different phenotypic dromedary camels showing highest in diluted and lowest in dark brown camels. B, MiR-129 melt-curve showing uniform expression at $790^{\circ} \mathrm{C}$. C, MiR-145 expression in different phenotypic dromedary camels showing highest expression in white and significantly low in dark brown camels. D, MiR-145 melt-curve showing uniform expression at $790 \mathrm{C}$.

A

$$
\begin{aligned}
& \text { XM } 010979466.2 \\
& \mathrm{mi} \overline{\mathrm{R}}-129-5 \mathrm{p}
\end{aligned}
$$

XM_010979466.2 $\operatorname{mi} \overline{\mathrm{R}}-145$
B

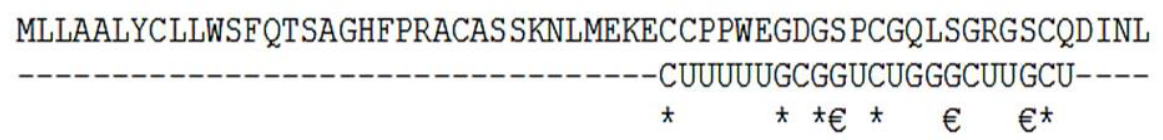

Fig. 3. MiRNAs binding to the TYR. A, XM_010979466.2-TYR protein and miRNA; B, sequence matching; C, Position of binding; *, identical, $€$, groups with weak similarity. 


\section{DISCUSSION}

This is the first study as per our knowledge to evaluate the TYR gene expression level in different dromedary phenotypic camels. The TYR gene involve in melanogenesis pathway switching to various coat colors and this is a conserved gene similar to that of humans and other species.

Some of the mutations in the TYR gene have been reported to alter the gene expression and phenotype color such as albino animals in various species (Anistoroaei et al., 2008; Blaszczyk et al., 2005; Schmutz et al., 2004; Imes et al., 2006). Missense mutations in 7 alleles of mice developed hypopigmentation (Challa et al., 2016). A hypopigmented minks were observed with the Himalayan allele due to the presence of snp (Benkel et al., 2009). We assessed the TYR gene of different phenotypic dromedary camels (white, black, diluted, and dark brown) for expression patterns.

We did the expression analysis of the TYR gene and observed with low expression in white phenotypes and increasing expression from diluted $>$ black $>$ dark brown coat colors. This might be due to the lesser expression of the Microphthalmia-associated transcription factor type $\mathrm{M}$ (MITF-M) gene which regulates the TYR gene (Anello et al., 2019). A very similar result was observed in llamas study by Anello et al. (2019) and Paterson et al. (2015) in mice phenotypes (Paterson et al., 2015). One of the studies on alpacas reported that the TYR gene along with the 7 other color related genes was expressed low in white, intermediate in the bay and high in black phenotypes (Munyard, 2013). Some of the similar studies of TYR gene expression in Korean cattle and Jining goats revealed that the pigmented ones expressed higher than the lighter or diluted phenotypes (Kim et al., 2014; Chen et al., 2012). In our study, the dark brown phenotypes showed higher expression than the black which could be due to less sample size and difference in expression. However, there could be similar mutations under various genetic environments that produce different genotypes as it was suggested in different strains of rabbits (Aigner et al., 2000). Moreover, other mutations may influence the actual coat color of the individual. Due to the less exploration and unavailability of complete sequencing data of this gene such as total exon sequencing it was not possible to correlate completely. Further study with more phenotypic samples and complete sequencing could be carriedout to correlate with the coat color. TYR is one of the key gene among other genes involved in melanin synthesis and rate-limiting enzyme. The MITF is the vital transcription factor for the TYR gene which induces the tyrosinase-related protein 1(TYRP1) and lead to the process of melanogenesis. Apart from the transcription factors and melanin synthesizing genes there are some miRNAs which have a significant regulatory role in melanin biosynthesis. A few of them are miR-129-5p, miR-145, miR434-5p, miR-25 which target the mRNA of TYR and MITF and downregulate or upregulate the melanin synthesis (Dynoodt et al., 2013; Li et al., 2020; Wu et al., 2008).

We selected miR-129-5p and miR-145 to evaluate the TYR expression. They were inversely proportional to the mRNA of the TYR gene expression. They bind to the mRNA of TYR gene and upregulate or downregulate its expression. Therefore, these two miRNAs were highly expressed in white and diluted phenotypes and low in black and dark brown ones (Fig. 2). This was consistent with the previous studies (Dynoodt et al., 2013; Li et al., 2020; Wu et al., 2008). Hence, it was correlated that the TYR expression with the miRNAs expression.

\section{CONCLUSION}

In this study, we analyzed the TYR gene of different phenotypic dromedary camels for its expression and association with the various coat colors. It was less expressed in white than the pigmented ones which were further evaluated with miRNAs expression. This study also revealed that the understanding of TYR gene expression and its influence on melanogenesis via non-coding miRNA regulatory markers. Our data are useful in understanding the phenotypic classification of the coat color.

\section{ACKNOWLEDGMENTS}

The authors extend their appreciation to the Deputyship for Research and Innovation, Ministry of Education in Saudi Arabia for funding this research work through the project number IFT20124.

\section{Supplementary material}

There is supplementary material associated with this article. Access the material online at: https://dx.doi. org/10.17582/journal.pjz/20210204120257

\section{Statement of conflict of interest}

The authors have declared no conflict of interests.

\section{REFERENCES}

Abdallah, H.R. and Faye, B., 2012. Phenotypic classification of Saudi Arabian camel (Camelus dromedarius) by their body measurements. Emir. J. Fd. Agric., 24: 272-280.

Aigner, B., Besenfelder, U., Müller, M. and Brem, G., 
2000. Tyrosinase gene variants in different rabbit strains. Mammal. Genome, 11: 700-702. https://doi. org/10.1007/s003350010120

Almathen, F., Elbir, H., Bahbahani, H., Mwacharo, J. and Hanotte, O., 2018. Polymorphisms in MC1R and ASIP genes are associated with coat color variation in the arabian camel. J. Heredity, 109: 700-706. https://doi.org/10.1093/jhered/esy024

Anello, M., Fernández, E., Daverio, M.S., Vidal Rioja, L.B. and di Rocco, F., 2019. TYR gene in llamas: Polymorphisms and expression study in different color phenotypes. Front. Genet., 10: 568. https:// doi.org/10.3389/fgene.2019.00568

Anistoroaei, R., Fredholm, M., Christensen, K. and Leeb, T., 2008. Albinism in the American mink (Neovison vison) is associated with a tyrosinase nonsense mutation. Anim. Genet., 39: 645-648. https://doi.org/10.1111/j.1365-2052.2008.01788.x

Beermann, F., Orlow, S.J. and Lamoreux, M.L., 2004. The Tyr (albino) locus of the laboratory mouse. Mammal. Genome, 15: 749-758. https://doi. org/10.1007/s00335-004-4002-8

Benkel, B.F., Rouvinen-Watt, K., Farid, H. and Anistoroaei, R., 2009. Molecular characterization of the Himalayan mink. Mammal. Genome, 20: 256-259. https://doi.org/10.1007/s00335-0099177-6

Blaszczyk, W.M., Arning, L., Hoffmann, K.P. and Epplen, J.T., 2005. A Tyrosinase missense mutation causes albinism in the Wistar rat. Pigm. Cell Res., 18: 144-145. https://doi.org/10.1111/j.16000749.2005.00227.x

Challa, A.K., Boitet, E.R., Turner, A.N., Johnson, L.W., Kennedy, D., Downs, E.R., Hymel, K.M., Gross, A.K. and Kesterson, R.A., 2016. Novel hypomorphic alleles of the mouse tyrosinase gene induced by CRISPR-Cas9 nucleases cause non-albino pigmentation phenotypes. PLoS One, 11: e0155812. https://doi.org/10.1371/journal. pone. 0155812

Chen, W., Wang, H., Dong, B., Dong, Z., Zhou, F., Fu, Y. and Zeng, Y., 2012. Molecular cloning and expression analysis of tyrosinase gene in the skin of Jining gray goat (Capra hircus). Mol. cell. Biochem., 366: 11-20. https://doi.org/10.1007/ s11010-012-1275-1

Damé, M.C.F., Xavier, G.M., Oliveira-Filho, J.P., Borges, A.S., Oliveira, H.N., Riet-Correa, F. and Schild, A.L., 2012. A nonsense mutation in the tyrosinase gene causes albinism in water buffalo. BMC Genet., 13: 1-7. https://doi.org/10.1186/14712156-13-62
Daverio, M.S., Rigalt, F., Romero, S., Vidal-Rioja, L. and di Rocco, F., 2016. Polymorphisms in MC1R and ASIP genes and their association with coat color phenotypes in llamas (Lama glama). Small Rum. Res., 144: 83-89. https://doi.org/10.1016/j. smallrumres.2016.08.003

Dynoodt, P., Mestdagh, P., Van Peer, G., Vandesompele, J., Goossens, K., Peelman, L.J., Geusens, B., Speeckaert, R.M., Lambert, J.L. and Van Gele, M.J., 2013. Identification of miR-145 as a key regulator of the pigmentary process. J. Invest. Derm., 133: 201-209. https://doi.org/10.1038/jid.2012.266

Eshra, E.A. and Badawy, A.M., 2014. Peculiarities of the camel and sheep narial musculature in relation to the clinical value and the mechanism of narial closure. Indian J. Vet. Anat., 26: 10-13.

Faye, B., 2018. The enthusiasm for camel production. Emir. J. Fd. Agric., 15: 249-250.

Faye, B. and Bonnet, P., 2012. Camel sciences and economy in the world: current situation and perspectives. Proc. $3^{\text {rd }}$ ISOCARD conference, Keynote presentations, 29th Jan.-1st Feb., pp. 2-15.

Holl, H., Isaza, R., Mohamoud, Y., Ahmed, A., Almathen, F., Youcef, C., Gaouar, S., Antczak, D.F. and Brooks, S., 2017. A frameshift mutation in KIT is associated with white spotting in the Arabian camel. Genes, 8: 102. https://doi.org/10.3390/ genes 8030102

Imes, D., Geary, L., Grahn, R.A. and Lyons, L.A., 2006. Albinism in the domestic cat (Felis catus) is associated with a tyrosinase (TYR) mutation. Anim. Genet., 37: 175-178. https://doi.org/10.1111/ j.1365-2052.2005.01409.x

Ishag, I., Reissmann, M., Eltaher, H. and Ahmed, M., 2013. Polymorphisms of Tyrosinase gene (exon 1) and its impact on coat color and phenotypic measurements of Sudanese camel breeds. Scient. J. Anim. Sci., 2: 109-115.

Kim, S.H., Hwang, S.Y. and Yoon, J.T., 2014. Microarray-based analysis of the differential expression of melanin synthesis genes in dark and light-muzzle Korean cattle. PLoS One, 9: e96453. https://doi.org/10.1371/journal.pone.0096453

Lamoreux, M.L., Wakamatsu, K. and Ito, S., 2001. Interaction of major coat color gene functions in mice as studied by chemical analysis of eumelanin and pheomelanin. Pigm. Cell Res., 14:23-31. https:// doi.org/10.1034/j.1600-0749.2001.140105.x

Li, J., Liu, L., Zhang, J., Cheng, L., Ren, L. and Zhao, Y., 2020. The expression of miR-129-5p and its target genes in the skin of goats. Anim. Biotechnol., 19: 1-7. https://doi.org/10.1080/10495398.2020.17 
30392

Li, Y.C., Korol, A.B., Fahima, T. and Nevo, E., 2004. Microsatellites within genes: Structure, function, and evolution. Mol. Biol. Evol., 21: 991-1007. https://doi.org/10.1093/molbev/msh073

Livak, K.J. and Schmittgen, T.D., 2001. Analysis of relative gene expression data using realtime quantitative PCR and the $2^{-\Delta \Delta \mathrm{ct}}$ method. Methods, 25: 402-408. https://doi.org/10.1006/ meth.2001.1262

Mahmoud, A.H., Saleh, A.A., Abasiry, A.M., Farah, M.A., Rady, A.M. and Sammour, R.H., 2020. Molecular characterization of tyrosinase gene (exon 1) in camels of Saudi Arabia. Indian J. Anim. Res., 54: 529-533.

Munyard, K., 2013. Inheritance of white colour in Alpacas: Identifying the genes involved. Rural Industries Research and Development Corporation, Australia.

Nowier, A.M., El-Metwaly, H.A. and Ramadan, S.I., 2020. Genetic variability of tyrosinase gene in Egyptian camel breeds and its association with udder and body measurements traits in Maghrebi camel breed. Gene Rep., 18: 100569. https://doi. org/10.1016/j.genrep.2019.100569

Orlow, S.J., Lamoreux, M.L., Pifko-Hirst, S. and Zhou, B.-K., 1993. Pathogenesis of the platinum (cp) mutation, a model for oculocutaneous albinism. J. Invest. Derm., 101: 137-140. https://doi. org/10.1111/1523-1747.ep12363621

Paterson, E.K., Fielder, T.J., MacGregor, G.R., Ito, S., Wakamatsu, K., Gillen, D.L., Eby, V., Boissy, R.E. and Ganesan, A.K., 2015. Tyrosinase depletion prevents the maturation of melanosomes in the mouse hair follicle. PLoS One, 10: e0143702. https://doi.org/10.1371/journal.pone.0143702

Schmutz, S.M., Berryere, T.G., Ciobanu, D.C., Mileham, A.J., Schmidtz, B.H. and Fredholm, M., 2004. A form of albinism in cattle is caused by a tyrosinase frameshift mutation. Mammal. Genome, 15: 62-67. https://doi.org/10.1007/s00335-002-2249-5

Shah, M., Reissmann, M., Qureshi, A. and Schwartz, H., 2009. Evaluation of six camel breeds for heterozygocity through restriction fragment length polymorphism. Pak. Vet. J., 29: 13-16.

Shah, M.G.U., Reissmann, M., Qureshi, A.S., Schwartz, H.J., Khan, M.S., Ali, T., Zaman, A., Safdar, K., Muhammad, K. and Ullah, S., 2012. Determination of genotype differences through restriction endonuclease in Camels (Camelus dromedarius). Afr. J. Biotechnol., 11: 11543-11547. https://doi. org/10.5897/AJB12.883

Sjakste, T., Paramonova, N. and Sjakste, N., 2013. Functional significance of microsatellite markers. Medicina, 49: 79. https://doi.org/10.3390/ medicina49120079

Utzeri, V., Bertolini, F., Ribani, A., Schiavo, G., Dall'Olio, S. and Fontanesi, L., 2016. The albinism of the feral Asinara white donkeys (Equus asinus) is determined by a missense mutation in a highly conserved position of the tyrosinase (TYR) gene deduced protein. Anim. Genet., 47: 120-124. https:// doi.org/10.1111/age.12386

Wu, D.T., Chen, J.S., Chang, D.C. and Lin, S.L., 2008. Mir-434-5p mediates skin whitening and lightening. Clin. Cosm. Invest. Derm., 1: 19. https:// doi.org/10.2147/CCID.S4181

Yokoyama, T., Silversides, D.W., Waymire, K.G., Kwon, B.S., Takeuchi, T. and Overbeek, P.A., 1990. Conserved cysteine to serine mutation in tyrosinase is responsible for the classical albino mutation in laboratory mice. Nucl. Acids Res., 18: 7293-7298. https://doi.org/10.1093/nar/18.24.7293

Zhu, Z., He, J., Jia, X., Jiang, J., Bai, R., Yu, X., Lv, L., Fan, R., He, X. and Geng, J., 2010. MicroRNA-25 functions in regulation of pigmentation by targeting the transcription factor MITF in alpaca (Lama pacos) skin melanocytes. Domest. Anim. Endocrinol., 38: 200-209. https://doi.org/10.1016/j. domaniend.2009.10.004 